\title{
IMAGES IN DERMATOLOgY
}

\section{Phenotypic spectrum of a patient with Gorlin's syndrome and role of dermoscopy in the early detection of basal cell carcinomas*}

\author{
Catarina Moreira ${ }^{1,2}$ \\ Paulo Santos ${ }^{1}$ \\ Filomena Azevedo ${ }^{1}$
}

\author{
Paulo Morais ${ }^{3}$ \\ Miguel Castro ${ }^{1}$
}

DOI: http:/ /dx.doi.org/10.1590/abd1806-4841.20153676

\begin{abstract}
A bstract: Gorlin's syndrome is an autosomal dominant disorder, mainly characterized by the presence of multiple and early-onset basal cell carcinomas, odontogenic keratocysts and palmoplantar pits. We describe the case of a patient with clinical and imaging features of Gorlin syndrome, and highlight the role of dermoscopy in the early detection of basal cell carcinomas. In addition, we discuss the dermoscopic features of palmar pits.
\end{abstract}

Keywords: Basal cell nevus syndrome; Carcinoma, basal cell; Dermoscopy; Radiology

\section{INTRODUCTION}

Gorlin's syndrome (GS) or nevoid basal cell carcinoma syndrome is an autosomal dominant disorder caused by mutations in PTC, the human homologue of the Drosophila patched gene. This condition has a variable phenotypic expression, probably due to the interaction of genetic and environmental factors. Common features include the presence of multiple and early-onset basal cell carcinomas (BCC), odontogenic keratocysts (OKC) of the jaw, palmoplantar pits, broad forehead, rib anomalies, calcified falx cerebri, and other developmental anomalies and neoplasms. ${ }^{1}$

\section{CASE REPORT}

A 50-year-old female with a history of uterine fibroma (UF) and right cheek BCC excised 26 and 7 years before, respectively, presented for the evaluation of 3 nodular lesions on the face, which were clinically suggestive of BCC. Additionally, she reported frequent back pain and exhibited multiple milia scat- tered over her face, coarse facies with hypertelorism and prognathism, and mild palmar pitting (Figure 1). Attentive skin examination and dermoscopy disclosed a total of 8 lesions suggestive of BCCs. The most commonly observed dermoscopy features were: arborizing vessels, ulceration, blue-gray globules and spokewheel areas (Figure 2). Dermoscopy also enabled a better visualization of the palmar pits, and revealed flesh-colored, irregular-shaped and slightly depressed lesions, some of them with red globules inside (Figure 3). The patient's mother had died at the age of 65 years due to destructive BCC of the periorbital area. Her 26-year-old daughter had a history of OKC of the jaw and UF excised at the ages of 17 and 19 years, respectively; 3 facial BCCs, the first having been removed at 19 years of age; hypertelorism; prognathism; milia on the face and severe palmar pits (Figure 4). Two of the proband's brothers had also underwent excision of multiple BCCs since their $4^{\text {th }}$ decade of life. Imag-

Received on 05.05.2014

Approved by the Advisory Board and accepted for publication on 14.08.2014

Study conducted at the Centro Hospitalar São João EPE - Porto, Portugal.

Financial Support: None.

Conflict of Interest: None.

Centro Hospitalar São João, EPE - Porto, Portugal.

Faculty of Medicine, University of Porto - Porto, Portugal.

Centro Hospitalar Tondela-Viseu, EPE - Viseu, Portugal.

C2015 by Anais Brasileiros de Dermatologia 

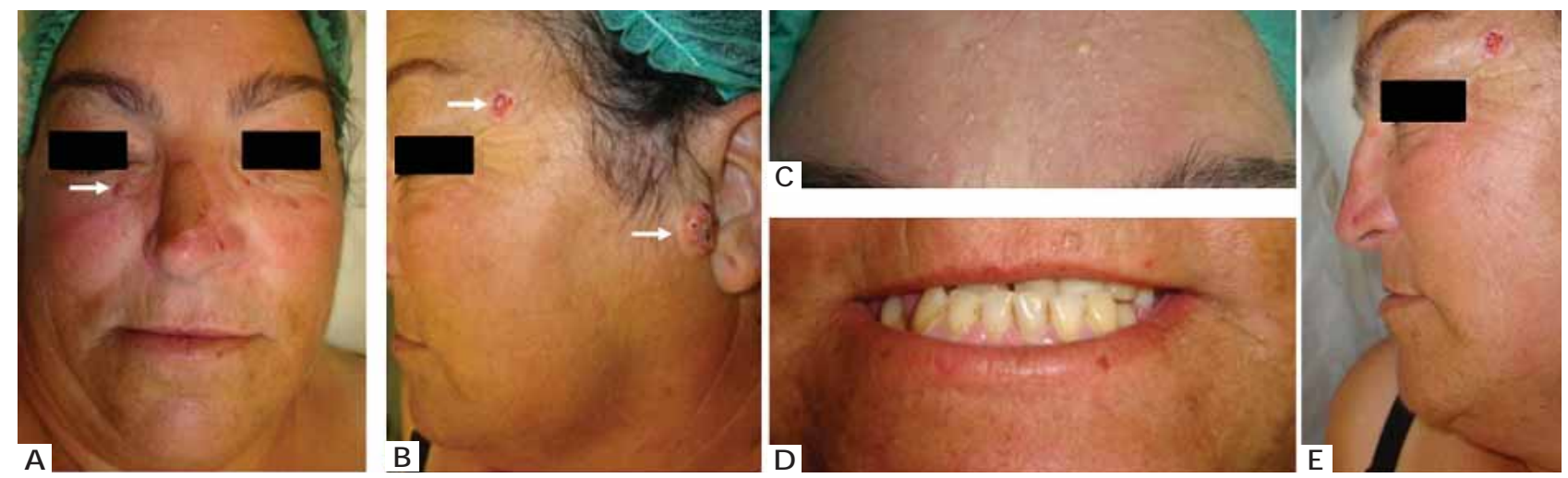

Figure 1: Patient's clinical appearance. Three nodular basal cell carcinomas (arrows), multiple milia (c) and coarse facies with hypertelorism and prognathism $(\mathbf{d}, \mathbf{e})$
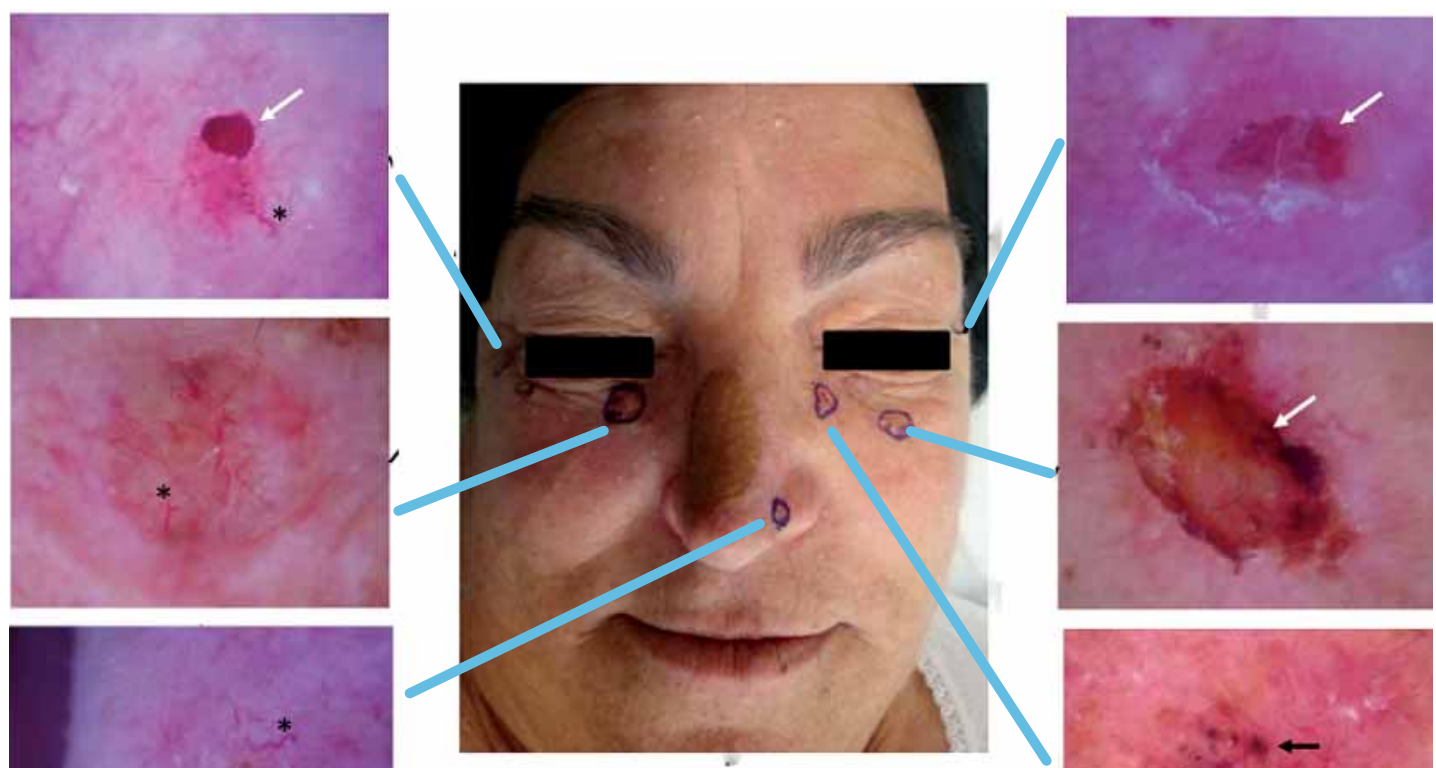

Figure 2:

Dermoscopic features of some basal cell carcinomas. Arborizing vessels (asterisks), ulcer-
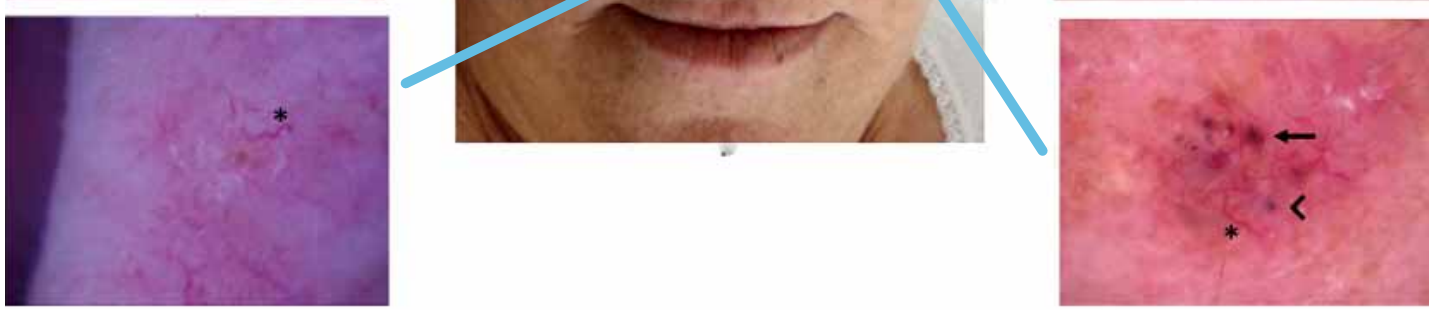
ation (white arrows), bluegray globules (head arrow) and spokewheel areas (black arrow)
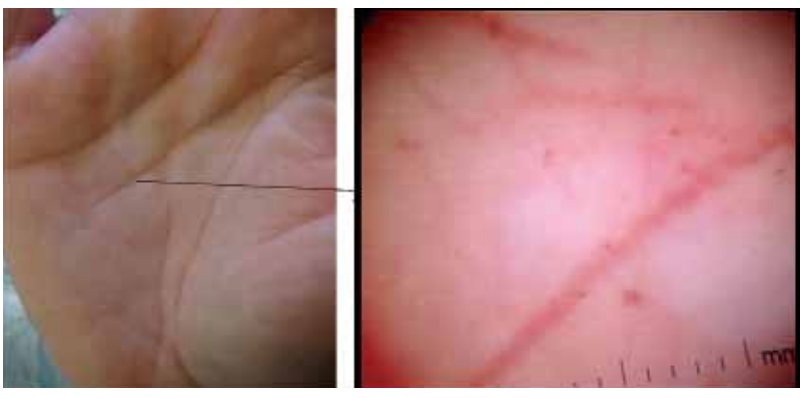

Figure 3: Dermoscopic features of palmar pitting. Flesh-colored, irregular-shaped and slightly depressed lesions, some with red globules

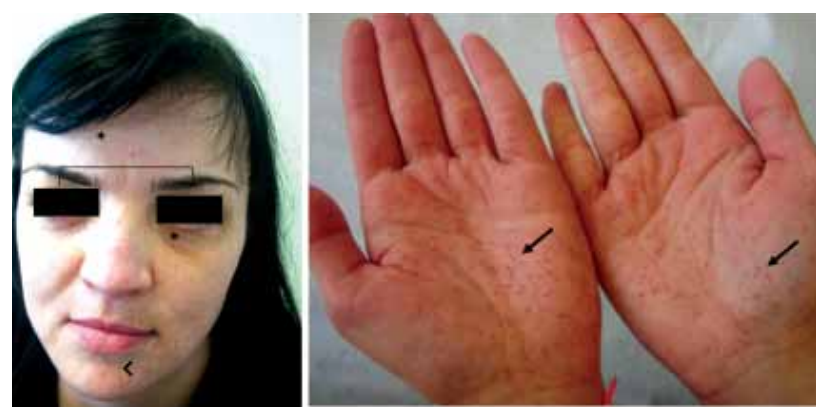

Figure 4: Patient's daughter's clinical appearance. Hypertelorism (line), prognathism (head arrow), milia (asterisks) and severe palmar pits (arrows) 
ing studies (skull, face, chest and spine X-ray and CT scan) disclosed calcification of the cerebral falx, OKC of the left jaw, bilateral bifid ribs, marked dextroconvex dorsal scoliosis associated with hemivertebra, and prominent transverse processes of C7 (Figure 5). ECG, abdomino-pelvic US and ophthalmological examination were normal. Based on the clinical and radiological features, and the family history, our patient was diagnosed as having a familial GS. The facial tumors were excised, and the diagnosis of BCC was confirmed histologically in all lesions included in this study.

\section{DISCUSSION}

The clinical diagnosis of GS is based on the presence of multiple BCCs and palmoplantar pits, in association with internal abnormalities and skeletal defects. With dermoscopy, BCCs in GS can be detected in early stages by the presence of typical, but often subtle, dermoscopic features of BCC. Acral pits, which are often overlooked during physical examination, have a characteristic dermoscopy and can be easily visualized with this tool., ${ }^{2,3}$ Additionally, the role of dermoscopy in predicting tumor subtype has been demonstrated, and this may influence the choice of treatment. Maple leaf-like areas, short fine superficial telangiectasia, multiple small erosions, and shiny white-red structureless areas seem to be potent predictors of superficial BCC, while the presence of ar- borizing vessels, blue-gray ovoid nests, and ulceration increases the possibility of the diagnosis of non-superficial BCCs. ${ }^{4}$

Although sporadic human BCC are generally well managed with excisional surgery, considering the number and characteristic recurrent nature of the lesions in GS, several alternative approaches have been used - alone or in combination -, including ablative laser therapy, electrocoagulation, cryosurgery, photodynamic therapy, topical imiquimod and 5-fluorouracil. ${ }^{5}$ Unfortunately, there are no large-scale studies on the treatment of BCCs in this syndrome. The choice of treatment is generally based on a combination of factors, which include: available clinical evidence, patient and tumor characteristics, patient's choice, local availability of specialized services, and experience and preferences of the physician. The development of an oral hedgehog pathway inhibitor, vismodegib, has raised a new dimension to the current treatment of BCCs. The recent demonstration that vismodegib additionally shrinks some OKCs in patients with GS will surely increase the interest in the drug when treating patients with this syndrome. ${ }^{6}$

This case was unusual in that the patient presented with most of the clinical and imaging criteria for diagnosing GS, as defined by Kimonis et al.. ${ }^{1}$ The decision to surgically excise the BCCs was based on several factors, such as clinical and dermoscopy fea-
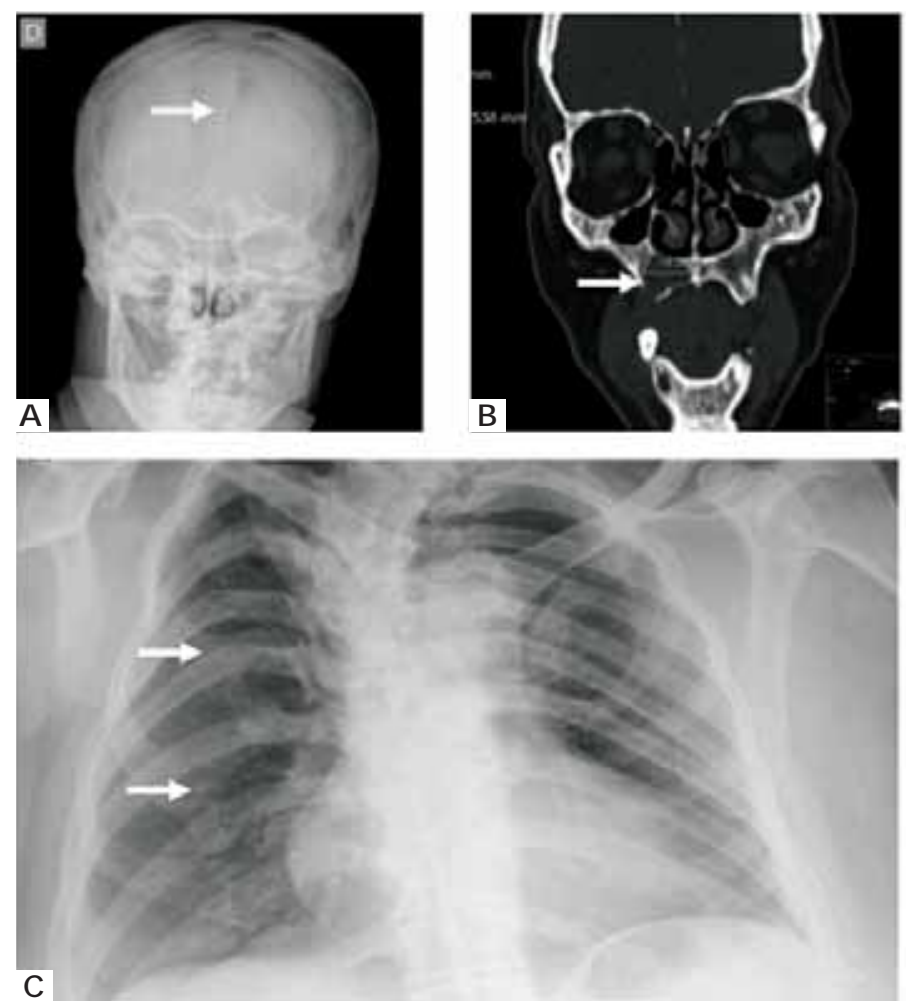

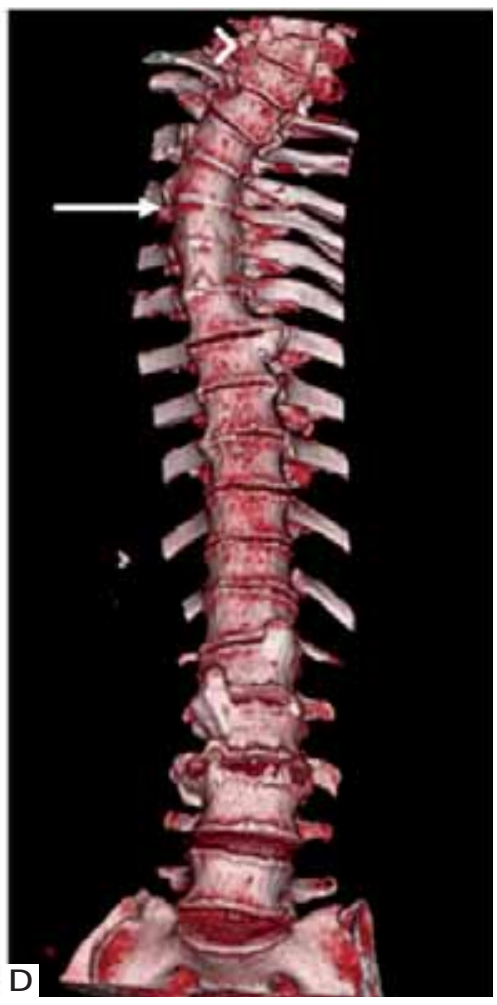

Figure 5:

Radiological findings. (a) Calcification of the cerebral falx, (b) odontogenic keratocysts of the maxilla, (c) bifid ribs, and (d) marked dextroconvex dorsal scoliosis (arrow) associated with hemivertebra (head arrow) 
tures predicting non-superficial subtype in most of the lesions, the patient's will, the availability of technics, and the experience and preference of the specialist physician involved.

We intend to emphasize that a regular dermatological examination is recommended for all patients with GS, so that BCCs can be early diagnosed and treated. A continuous and multidisciplinary approach, as well as a follow-up are essential, given the diverse clinical manifestations patients can present throughout life. These recommendations might help avoid possible complications and thus improve quality of life.]

\section{REFERENCE}

1. Kimonis VE, Goldstein AM, Pastakia B, Yang ML, Kase R, DiGiovanna JJ, et al. Clinical manifestations in 105 persons with nevoid basal cell carcinoma syndrome. Am J Med Genet. 1997;69:299-308.

2. Kolm I, Puig S, Iranzo P, Malvehy J. Dermoscopy in Gorlin-Goltz syndrome. Dermatol Surg. 2006;32:847-51.

3. Tiodorovic-Zivkovic D, Zalaudek I, Ferrara G, Giorgio CM, Di Nola K, Procaccini EM, et al. Clinical and dermatoscopic findings in Bazex-Dupré-Christol and GorlinGoltz syndromes. J Am Acad Dermatol. 2010;63:722-4.

4. Lallas A, Tzellos T, Kyrgidis A, Apalla Z, Zalaudek I, Karatolias A, et al. Accuracy of dermoscopic criteria for discriminating superficial from other subtypes of basal cell carcinoma. J Am Acad Dermatol. 2014;70:303-11.

5. van der Geer S, Ostertag JU, Krekels GA. Treatment of basal cell carcinomas in patients with nevoid basal cell carcinoma syndrome. J Eur Acad Dermatol Venereol. 2009;23:308-13.

6. Ally MS, Tang JY, Joseph T, Thompson B, Lindgren J, Raphael MA, et al. The use of vismodegib to shrink keratocystic odontogenic tumors in patients with Basal cell nevus syndrome. JAMA Dermatol. 2014;150:542-5.

\author{
M AILING ADDRESS: \\ Catarina da Cunha M oreira \\ A lameda Prof. Hernani M onteiro \\ 4200-319 - Porto - Portugal \\ E-mail: cat_moreira@icloud.com
}

How to cite this article: Moreira C, Morais P, Santos P, Castro M, Azevedo F. Phenotypic spectrum of a patient with Gorlin's syndrome and role of dermoscopy in the early detection of basal cell carcinomas. An Bras Dermatol. 2015; 90(3):416-9. 